\title{
VI-RADS for Bladder Cancer: Current Applications and Future Developments
}

\author{
Valeria Panebianco, MD, ${ }^{1 \dagger \star}$ (1) Martina Pecoraro, MD, ${ }^{1}$ Francesco Del Giudice, MD, ${ }^{2}$ \\ Mitsuru Takeuchi, PhD, ${ }^{3}$ Valdair F. Muglia, PhD, ${ }^{4}$ (D) Emanuele Messina, MD, ${ }^{1}$ \\ Stefano Cipollari, MD, ${ }^{1}$ Gianluca Giannarini, MD, ${ }^{5}$ (D) Carlo Catalano, MD, ${ }^{1}$ and \\ Yoshifumi Narumi, PhD ${ }^{6+}$
}

Bladder cancer ( $\mathrm{BCa}$ ) is among the ten most frequent cancers globally. It is the tumor with the highest lifetime treatmentassociated costs, and among the tumors with the heaviest impacts on postoperative quality of life. The purpose of this article is to review the current applications and future perspectives of the Vesical Imaging Reporting and Data System (VIRADS). VI-RADS is a newly developed scoring system aimed at standardization of MRI acquisition, interpretation, and reporting for $\mathrm{BCa}$. An insight will be given on the BCa natural history, current MRI applications for local BCa staging with assessment of muscle invasiveness, and clinical implications of the score for disease management. Future applications include risk stratification of nonmuscle invasive $\mathrm{BCa}$, surveillance, and prediction and monitoring of therapy response.

Level of Evidence: 3

Technical Efficacy Stage: 2

J. MAGN. RESON. IMAGING 2020.

$\mathrm{B}^{1}$ LADDER CANCER (BCa) is among the ten most frequent cancers globally. ${ }^{1}$ Every year $\sim 550,000$ people are diagnosed with bladder cancer. ${ }^{2}$ Major risk factors for the development are cigarette smoking, with a population-attributable risk of BC of about $40 \%,{ }^{3}$ and other environmental factors such as exposure to chemicals and industrial pollutants.

The initial diagnostic workup for $\mathrm{BCa}$ involves ultrasound (US) or cystoscopy as first-line tests, followed by diagnostic transurethral resection of bladder tumor (TURBT) for the confirmatory pathology. Around $70 \%$ of tumors are nonmuscle-invasive bladder cancer (NMIBC), and more than $50 \%$ are Ta stage tumors. ${ }^{1,4}$ Although the majority of cases are diagnosed at a nonmuscle-invasive stage, $\sim 200,000$ deaths occur each year due to $\mathrm{BCa} .^{5}$ The rate of progression and recurrence of the disease is high; nearly three-fourths of patients diagnosed with high-risk BCa will recur, progress, or die within 10 years from their diagnosis, partly due to the inaccuracies of the diagnostic procedure. ${ }^{6}$ Epidemiological studies show that between $30 \%$ and $45 \%$ of deaths are preventable. $^{7}$

Mortality among different countries is heterogeneous, with the highest rates observed in countries such as the Middle East and North Africa. ${ }^{8}$ There is a significant relation between $\mathrm{BCa}$ mortality and the world development index, strengthening the hypothesis that a higher degree of socioeconomic development is able to provide earlier diagnosis and more appropriate treatment. BCa survival is strongly dependent on the treatment delivered, rather than the intrinsic aggressiveness of the tumor. ${ }^{9}$ High rates of inaccuracy are not only responsible for the increased morbidity and mortality, but they also translate into higher costs. With the current diagnostic protocol, the risk of residual disease after initial TURBT may be as high as $50-70 \%$, with the need to perform an additional tumor resection (re-TURBT) for restaging the tumor. ${ }^{10}$ This constitutes a significant preventable

View this article online at wileyonlinelibrary.com. DOI: 10.1002/jmri.27361

Received Apr 16, 2020, Accepted for publication Aug 27, 2020.

*Address reprint requests to: V.P., Viale del Policlinico 155, 00161 Rome, Italy. E-mail: valeria.panebianco@uniroma1.it

${ }^{\dagger}$ These authors contributed equally.

From the ${ }^{1}$ Department of Radiological Sciences, Oncology and Pathology, Sapienza/Policlinico Umberto I, Rome, Italy; ${ }^{2}$ Department of Maternal-Infant and Urological Sciences, Sapienza/Policlinico Umberto I, Rome, Italy; ${ }^{3}$ Department of Radiology, Radiolonet Tokai, Nagoya, Japan; ${ }^{4}$ Department of Medical Images, Radiation Therapy and Oncohematology, Ribeirao Preto Medical School, University of Sao Paulo, Ribeirao Preto, Brazil; ${ }^{5}$ Urology Unit, Academic Medical Centre "Santa Maria della Misericordia", Udine, Italy; and 'Department of Healthcare, Tachibana University, Kyoto, Japan 
expense, considering the additional surgerical procedure and hospital admissions that it requires. It is not a surprise that $\mathrm{BCa}$ is currently the tumor with the highest lifetime treatment-associated costs, with around $\$ 185,000$ expenditure per case, and around $\$ 4$ billion national costs of cancer care in the U.S. per year. ${ }^{11,12}$ Despite the advancements in surgical and pharmacologic treatment, the primary diagnostic and therapeutic planning still need to be improved: $\mathrm{BCa}$ is currently among the tumors with the heaviest impacts on postoperative quality of life. ${ }^{13-15}$ An implementation of the accuracy of the primary staging of the tumor is of vital importance at the present time, for different pathologies. ${ }^{16-19}$

In order to optimize the diagnostic pathway and minimize costs related to BCa management, new diagnostic techniques are being proposed. Preoperative multiparametric magnetic resonance imaging (MRI), with the use of the Vesical Imaging Reporting and Data System (VI-RADS) scoring system seems to constitute a possible solution to this issue.

\section{Bladder Anatomy and Bladder Cancer}

The bladder is a hollow pelvic organ, connected to the ureters and to the urethra. As part of the urinary system, it is devoted to the collection of urine: it can accommodate $400-600 \mathrm{~mL}$ of urine (full distension), owing to the unique properties of its anatomy. The urothelium is a pseudostratified columnar epithelium composed of three cell types-the apical umbrella, the medial, and the basal cells-highly modifiable in shape. ${ }^{20}$ The pseudostratified epithelium can display up to seven layers of cells, sliding one or the other over a single basement membrane. Underlying the mucosa, the lamina propria is found, a highly vascularized layer of connective tissue. The outer layer is the muscularis propria (made of three well-represented layers of smooth muscle tissue: an inner longitudinal, a middle circular, and an outer longitudinal). The outermost layer is the adventitia: mesenchymal tissue that envelops the bladder and makes contact with the nearby infraperitoneal organs. ${ }^{21}$ Thanks to the characteristics of its tissues, the bladder can display outstanding distensible properties and contractile strength at the same time.

The most frequent histologic variant of $\mathrm{BCa}$ is urothelial cell carcinoma, accounting for more than $90 \%$ of all cases; other lesser variants are squamous cell carcinoma, adenocarcinomas, and lymphomas. ${ }^{22}$ Urothelial carcinoma is an epithelial tumor arising from transitional cells of the bladder mucosa. It typically displays multifocal and a recurrent nature. ${ }^{2,24}$ The morphology of the tumor is variable, and the different variants can sometimes constitute a continuum in the evolution of the neoplasm. The primary tumor can form exophytic polypoid masses, or sessile infiltrative lesions; carcinoma-in-situ (CIS) instead has a horizontal, highly invasive growth. Invasion of the muscularis propria (pT2) is a key predictive and prognostic factor: there is a considerable drop in prognosis from nonmuscle-invasive and muscle-invasive $\mathrm{BCa} \cdot{ }^{25}$ For this reason, the pathologic and radiologic assessment of muscle invasion is of fundamental importance, and affects therapeutic planning dramatically. ${ }^{26}$

\section{Bladder Cancer Staging and MRI}

The TNM system is used to stage BCa. ${ }^{27}$ Ta tumor infiltrates the innermost layer of the bladder lining. T1 cancer grows into the connective tissue, not invading the detrusor muscle layer. T2 cancer has grown into the muscle, with T2a into the superficial and T2b into the deeper lining. T3 cancer has grown into the adipose tissue layer, with T3a and T3b representing microscopic and macroscopic invasion, respectively. T4 cancer spreads outside the bladder, with T4a to adjacent organs and T4b to distant tissues, outside pelvis and abdomen. Therefore, BCa staged $\leq \mathrm{T} 1$ is defined as NMIBC and $\geq \mathrm{T} 2 \mathrm{a}$ as MIBC, the two having very different prognosis and therapeutic planning. It is essential to accurately differentiate NMIBC and MIBC, since the two require very distinct management. In the setting of $\mathrm{BCa}$ staging, MRI of the urinary bladder has proven to be able to accurately differentiate NMIBC from MIBC. MRI strengths lie in its high spatial resolution and soft-tissue contrast. ${ }^{28-30}$

Local staging is performed, evaluating the presence of muscle-invasiveness (T1 vs. T2 stage), perivesical fat invasion (T3 stage), adjacent structure involvement (T4 stage), and assessment of pelvic lymph nodes ( $\mathrm{N}$ stage), and bones (M stage). MRI can properly assess local staging thanks to morphological $\mathrm{T}_{2}$-weighted images $\left(\mathrm{T}_{2} \mathrm{WI}\right)$ associated with functional diffusion-weighted images (DWI) / apparent diffusion coefficient (ADC map), and dynamic contrast-enhanced MRI (DCE) sequences. $T_{2}$ WI allows the evaluation of the location, size, and morphology of bladder lesions, and reduces staging errors thanks to its high signal-to-noise ratio (SNR) and excellent anatomical visualization. ${ }^{31}$ MRI functional sequences application has further increased the accuracy of the technique. ${ }^{32-34}$ On $\mathrm{T}_{2} \mathrm{WI}, \mathrm{BCa}$ usually has a signal intensity (SI) intermediate to urine and muscle. The detrusor muscle has a low SI on $\mathrm{T}_{2} \mathrm{WI}$, and if discontinuous should raise suspicion of T2 stage tumor. ${ }^{35-37}$ On DWI, BCa is typically hyperintense (with correspondingly low ADC values), the normal muscle layer is of intermediate SI. $^{38,39}$ In 2009, Takeuchi et $\mathrm{al}^{33}$ described the inchworm sign recognized in stalked exophytic tumors, representing the arch-shaped hyperintense appearance of the tumor over the hypointense submucosal stalk. They proposed the sign, indicative of a pT1 or lower tumor, as an imaging biomarker to predict tumor aggressiveness. On DCE MRI, tumors show early enhancement after contrast injection, with the detrusor muscle generally showing late enhancement; muscle-invasiveness (T2 stage) is suspected whenever the detrusor muscle shows early enhancement. ${ }^{35,38,40,41}$ MRI cannot identify CIS. ${ }^{42}$ 
Differentiation between $\mathrm{T} 2 \mathrm{a}$ and $\mathrm{T} 2 \mathrm{~b}$ is defined due to the prognostic significance, with T2b patients carrying a significantly increased risk for lymph node metastasis $(14 \%$ vs. $30 \%$, respectively) and decreased survival rates ${ }^{43}$; T2 substaging is not feasible with MRI; however, patient management does not change in these two categories. ${ }^{42}$ T3a categorization is not feasible with MRI, and it can only be assigned on pathology specimens. ${ }^{44}$ Again, the management for both T2 and T3a is the same. ${ }^{45,46}$ Fat tissue macroscopic involvement (T3b) is assessed with MRI, with the tumor extending to the perivesical adipose tissue on both $\mathrm{T}_{2} \mathrm{WI}$ and DW images, associated with irregularity of the bladder wall and postcontrast enhancement. ${ }^{31,46}$ Whenever there is disruption of the normal SI and morphology of adjacent organs on $\mathrm{T}_{2} \mathrm{WI}$ and the DWI/ADC map with associated early enhancement, direct extension of the tumor into the adjacent organ should be suspected and staged as T4 tumor. ${ }^{31,47}$ In 2015, Gandhi et al ${ }^{48}$ published results of a meta-analysis carried out on about 5000 patients, showing that MRI should be considered as potentially superior to the current standard for clinical staging for $\leq \mathrm{T} 1$ vs. $\geq \mathrm{T} 2$, $\leq \mathrm{T} 2$ vs. $\geq \mathrm{T} 3$, and $<\mathrm{T} 4 \mathrm{~b}$ vs. pT4b, not for T-any vs. T0. In 2017, a meta-analysis by Woo et $\mathrm{al}^{49}$ showed a pooled sensitivity and specificity of 0.92 and 0.87 , respectively, for differentiating stage $\mathrm{T} 1$ tumors from T2 or higher. In 2018, in a similar research Huang et $\mathrm{al}^{50}$ showed a pooled sensitivity and specificity of 0.90 and 0.88 , respectively, with results going up to 0.92 and 0.96 when MRI was performed with a $3 \mathrm{~T}$ scan, with DWI as part of the acquisition protocol. In 2019, Zhang et al ${ }^{51}$ published a meta-analysis on the diagnostic accuracy of MRI as a staging tool for $\mathrm{BCa}$ with a total of 140 studies included, showing a pooled sensitivity of 0.84 ( $95 \%$ confidence interval $[\mathrm{CI}]=0.79-0.89)$, specificity of $0.91(95 \% \mathrm{CI}:=0.87-$ 0.93 ), and an area under the curve (AUC) of 0.946.

\section{VI-RADS}

In 2018, a panel of multidisciplinary experts developed, through consensus using existing literature, the VI-RADS to standardize MRI acquisition and interpretation for BCa. ${ }^{42}$

\section{The Protocol}

PATIENT PREPARATION. Based on the VI-RADS document, antispasmodic agents could be administered so as to minimize motion and susceptibility artifacts from bowel peristalsis, thus improving imaging acquisition. The application of saturation bands on the anterior abdominal wall can reduce respiratory influences.

Adequate distension of the bladder is vital to avoid false positives and negatives due to up- and understaging. Patients are instructed to void 1-2 hours before imaging and to drink $500-1000 \mathrm{~mL}$ of water in the 30 minutes before the examination, depending on individual tolerance. MRI can be used as real-time imaging to determine bladder filling. Patients with an underdistended bladder should repeat the scan after 30-60 minutes; those with an overdistended bladder should void and start drinking again. ${ }^{42}$ The optimal bladder volume for imaging is around $300 \mathrm{~mL}$; therefore, in patients with a urethral catheter, $250-400 \mathrm{~mL}$ sterile saline can be used to distend the bladder. ${ }^{31}$

MRI ACQUISITION PROTOCOL. The minimal acquisition protocol consists of a combination of high-resolution $\mathrm{T}_{2} \mathrm{WI}$ on three planes (axial, coronal, and sagittal), and two functional MRI techniques: DWI and DCE MRI. A $\mathrm{T}_{1}$-weighted $\left(\mathrm{T}_{1} \mathrm{~W}\right)$ image is used to detect the presence of blood products and clot in the bladder, and bone metastasis. All the sequences should display the whole bladder, proximal urethra, pelvic nodes and pelvic viscera (prostate, seminal vesicles, uterus, ovaries, fallopian tubes, and vagina). The use of a high-field scan (1.5 or $3.0 \mathrm{~T}$ ) is recommended to achieve appropriate spatial resolution and SNR. A multichannel phased array body surface coil with at least 16 channels is also recommended. ${ }^{16}$ An overview of setting recommendations is presented in Table 1.

$T_{2}$-Weighted Images. $\mathrm{T}_{2} \mathrm{WI}$ shows the bladder anatomy and is used for tumor detection, localization, evaluation of the size, and morphology. $2 \mathrm{D}$ or $3 \mathrm{D}$, fast-spin-echo (FSE) or turbo-spin-echo sequences are acquired with a slice thickness of 3-4 mm and a small field of view (FOV), to achieve appropriate spatial resolution with an acceptable SNR. Images acquired with isotropic voxels can be reformatted using a plane perpendicular to the tumor base. ${ }^{52,53}$

Diffusion-Weighted Images. DWI reflects the Brownian motion of water molecules and it is a key component of the bladder MRI examination. An axial breathing-free spin-echo EPI sequence with spectral fat saturation is recommended. Acquisition of DW images on the coronal and/or sagittal plane can be performed, especially when tumors are localized at the bladder dome. A DWI sequence consists of multiple b values; typically b $800-1000 \mathrm{~s} / \mathrm{mm}^{2}$ are required; a very high $\mathrm{b}$ value may degrade SNR. ${ }^{33,54}$ Anatomical location is a limit of DWI, and it requires matching with the $\mathrm{T}_{2} \mathrm{~W}$ images. To minimize mismatch, it is important to have a homogenous magnetic field. ${ }^{46}$ DWI is sensitive to artifacts caused by field inhomogeneities. To reduce artifacts, to achieve a more homogenous field, and to minimize bowel movement, a short echo time (TE) can be used and a small shim box can be applied around the bladder. ${ }^{55}$ Recently, Warndahl et $\mathrm{al}^{56}$ proposed a new DWI sequence for the detection of prostate cancer, that could be applyed to the bladder. It is acquired with a $2 \mathrm{D}$ spatially selective, echo-planar RF pulse to excite a limited extent in the phase FOV direction, showing lower 
TABLE 1. Summary Table With MRI Settings at Both 1.5T and 3T Scanner

\begin{tabular}{|c|c|c|c|c|c|c|}
\hline \multirow{3}{*}{$\begin{array}{l}\text { MRI parameter setting at } \\
\text { TR (msec) }\end{array}$} & \multicolumn{2}{|l|}{$\underline{\mathbf{T}_{2} \mathbf{W}}$} & \multicolumn{2}{|l|}{ DWI } & \multicolumn{2}{|l|}{ DCE MRI } \\
\hline & $1.5 \mathrm{~T}$ & $3.0 \mathrm{~T}$ & $1.5 \mathrm{~T}$ & $3.0 \mathrm{~T}$ & $1.5 \mathrm{~T}$ & $3.0 \mathrm{~T}$ \\
\hline & 5000 & 4690 & 4500 & $\begin{array}{l}2500 \text { up } \\
\text { to } 5300\end{array}$ & 3.3 & 3.8 \\
\hline TE (msec) & 80 & 119 & 88 & 61 & 1.2 & 1.2 \\
\hline Flip angle (degree) & 90 & 90 & 90 & 90 & 13 & 15 \\
\hline FOV $(\mathrm{cm})$ & 23 & 23 & 27 & 32 & 35 & 27 \\
\hline Matrix & $256 \times 189-256$ & $400 \times 256-320$ & $128 \times 109$ & $128 \times 128$ & $256 \times 214$ & $192 \times 192$ \\
\hline Slice thickness (mm) & 4 & $3-4$ & 4 & $3-4$ & 2 & 1 \\
\hline Slice gap (mm) & $0-0.4$ & $0-0.4$ & $0-0.4$ & $0.3-0.4$ & 0 & 0 \\
\hline Number of excitations & $1-2$ & $2-3$ & $10-15$ & $4-10$ & 1 & 1 \\
\hline $\mathrm{b}$ value & & & $0-800-1000$ & $\begin{array}{l}0-800-1000 \\
\quad \text { (up to) } \\
2000 \mathrm{~s} / \mathrm{mm}^{2}\end{array}$ & & \\
\hline
\end{tabular}

DCE = dynamic contrast enhancement; DWI = diffusion-weighted imaging; FOV = field of view; MRI = magnetic resonance imaging; $\mathrm{TE}=$ echo time; $\mathrm{TR}=$ repetition time; $\mathrm{T}_{2} \mathrm{WI}=\mathrm{T}_{2}$ weighted imaging.

susceptibility to field inhomogeneity and significant improvement in interreader agreement and image quality.

Dynamic Contrast-Enhanced MRI. DCE MRI is the final key component of the VI-RADS and bladder MRI acquisition protocol. It reflects tissue vascularity and microvessel permeability. An axial 3D $T_{1}$ gradient echo (GRE) sequence with fat suppression is the preferred sequence, allowing higher spatial resolution. When acquired in $3 \mathrm{D}$, images can be reformatted on different planes, which should be perpendicular to the tumor base.

Images are acquired in the precontrast phase and during injection of a gadolinium-based contrast agent. It is administered using an injector system $(0.1 \mathrm{mmol} / \mathrm{kg}$ of body weight $)$ at a rate of $1.5-2.0 \mathrm{~mL} / \mathrm{s}$ if a standard relaxivity agent is used and followed by a saline flush. A high temporal resolution of $<15$ seconds is used to show early enhancement of the tumor. Signal contrast in the inner layer and the muscularis layer decreases with time; therefore, it is not useful to acquire latephase images for $\mathrm{T}$ staging. ${ }^{42}$

The original VI-RADS document specifies the technical requirements and the acquisition protocol of MRI of the bladder. $^{42}$

\section{Semeiotics and Reporting}

MRI spatial resolution allows to differentiate the bladder "inner layer" (mucosa and lamina propria) from the "outer layer" (muscularis propria) and from the perivesical fat tissue. Specifically, in healthy tissue the "inner layer" is not visualized on either $\mathrm{T}_{2} \mathrm{~W}$ or $\mathrm{DW}$ images; instead, the detrusor muscle appears as a low SI line on $\mathrm{T}_{2} \mathrm{~W}$ images, and as an intermediate SI line on DWI and ADC, where urine appears hypo- and hyperintense, respectively. On DCE, the "inner layer" shows early enhancement (hyperintense line); instead, the outer layer shows a more delayed and progressive enhancement. When muscle invasiveness is present, the outer layer immediately below the bladder tumor enhances well.

Diffuse or focal thickening of the bladder wall may appear because of an evolving inflammatory process and/or as a consequence of prior tumor resection, involving the "inner layer" (mucosa and lamina propria). In such cases, a thickened high SI line can be seen on $\mathrm{T}_{2} \mathrm{~W}$ images representing the edematous inner layer overlaying the low SI muscular layer; on DWI the edematous mucosa is seen as a relatively hypointense line. ${ }^{37-39}$

Tumor morphology should be assessed on $\mathrm{T}_{2} \mathrm{~W}$ images. BCa can take several forms: it can be sessile or papillary, and it can show an endo- or exophytic growth pattern; they can also be flat or mixed. Papillary tumors can be broad-based or pedunculated. Pedunculated papillary tumors show a better prognosis than the rest of the $\mathrm{BCa}$ forms. ${ }^{38}$

The most common location of tumor growth is the lateral walls and the bladder base. Few authors have correlated the location of the tumor with a more severe prognosis, with bladder tumor arising from the bladder neck having the worst prognostic significance. ${ }^{57,58}$ The VI-RADS document recommends the use of a schematic bladder map, to further standardize reporting. The presence of multiple tumors should be 
recorded, specifying the number of lesions, the size of the largest tumor, and the tumor with the more advanced appearance (highest suspected stage). ${ }^{42}$

\section{The Score}

VI-RADS is a 5-point category scale for MRI of the bladder that allows the radiologist to assign a numerical category to bladder lesions that defines the risk of muscle invasiveness. The score comprises five categories, from 1 to 5 , with VIRADS 1 and 2 representing very low and low likelihood of muscle invasiveness (Fig. 1); VI-RADS 3 reflecting an equivocal category (Fig. 2); VI-RADS 4 and 5, a high and very high likelihood of muscle invasiveness (Figs. 3, 4). In order to minimize the number of false-negative results that would dramatically change the prognostic outcome, VI-RADS $\geq 3$ has been suggested as muscle-invasive bladder cancer; however, VI-RADS $\geq 4$ is also potentially useful.

The goal of the VI-RADS is to standardize and optimize the image acquisition of MRI of the bladder and to standardize reporting, focused on accurate and reproducible local staging of BCa. It is meant to be applied to untreated patients and to patients having received diagnostic TURBT, before re-TURBT. ${ }^{42}$
According to VI-RADS, BCa on MRI is defined as an intravesical lesion with $T_{2}$ signal intensity intermediate to urine and muscle, a high signal intensity on DWI, matching to a low signal intensity at the ADC map, with early enhancement at DCE-MRI.

Tumors should be assessed on $\mathrm{T}_{2} \mathrm{~W}$ images, DWI, and DCE singularly, to create an overall risk of the invasion score. The VI-RADS algorithm for overall score assessment sees $\mathrm{T}_{2} \mathrm{~W}$ images as the "first-pass" sequence for BCa staging for a VI-RADS score from 1 to 3, and DWI (first) and DCE (second; especially if the DWI is suboptimal in quality) as the dominant sequences for risk estimates of scores 4 and $5 .{ }^{42} \mathrm{~A}$ summary of the pathological staging correlation with the final VI-RADS score according to single categories is depicted in Table 2.

ASSESSMENT ON $T_{2} W I$. The single assessment on $T_{2} W$ images defines the structural category (SC). Interruption of the low SI line representing the muscularis propria, on $\mathrm{T}_{2} \mathrm{~W}$ images, should raise suspicion of muscle-invasive bladder cancer ( $\geq \mathrm{T} 2$ stage). SC 1 and 2 is assigned to lesions associated with an uninterrupted low SI line representing the integrity of muscularis propria, smaller or larger than $1 \mathrm{~cm}$,
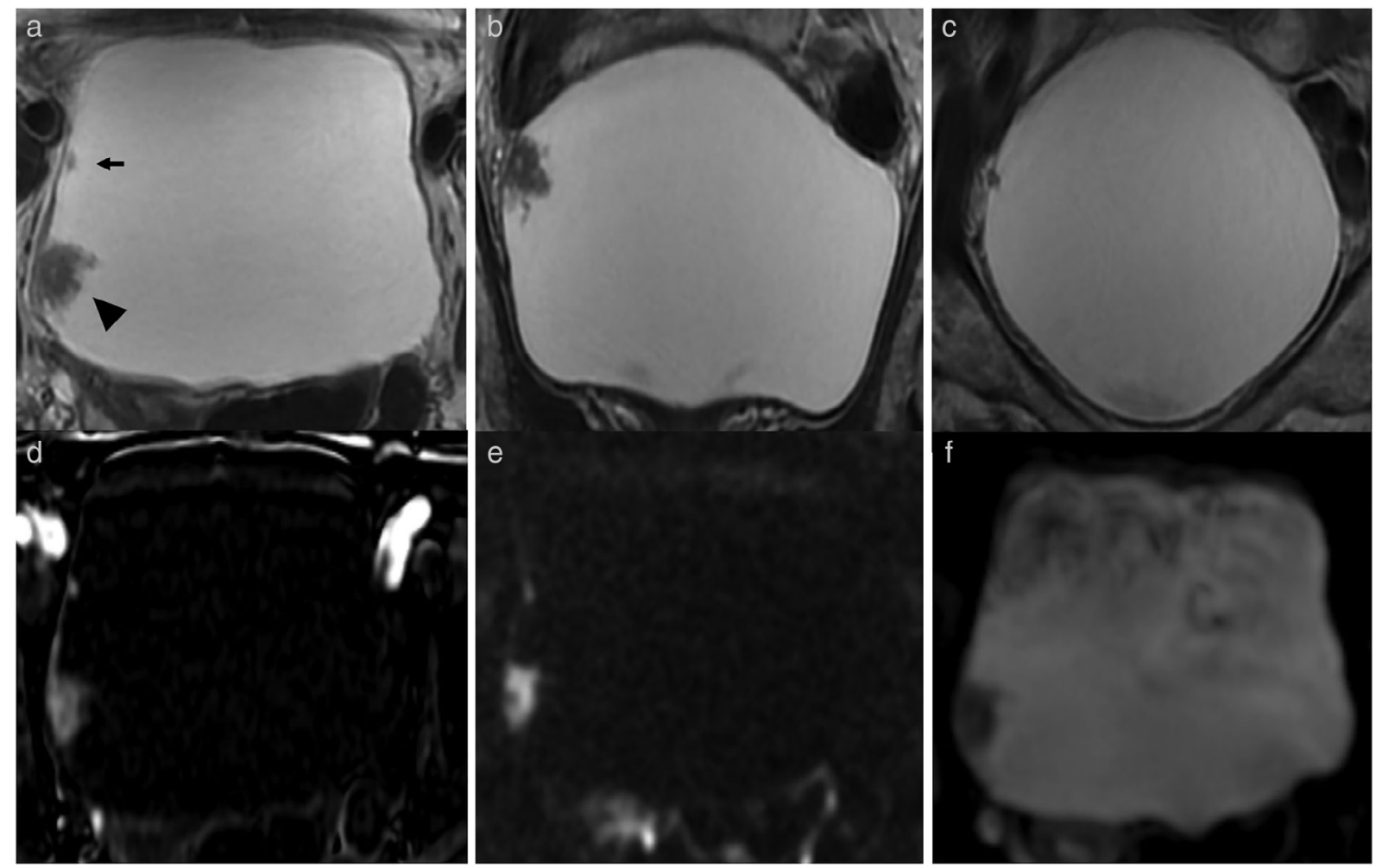

FIGURE 1: A 64-year-old female with positive cystoscopy. (a-c) $T_{2} W$ imaging (axial, coronal plane) shows two pedunculated masses, one $<1 \mathrm{~cm}$ in size (arrow) and one $>1 \mathrm{~cm}$ in size (arrowhead), both in the right lateral bladder wall, the smaller localized more anteriorly, both with intermediate $\mathrm{SI}$ not extending through the muscularis propria. $\mathrm{T}_{2} \mathrm{~W}$ imaging assigned as VIRADS categories 1 and 2, respectively. (d) DCE imaging shows early and heterogeneous enhancement of the lesions, not extending through the muscularis propria; enhancement of the inner layer can be appreciated. DCE assigned as VI-RADS categories 1 and 2, respectively. $(e, f) D W I(b=2000)$ and $A D C$ maps show significant restricted diffusion, not extending through the muscularis propria; the inchworm sign can be appreciated at the posterior lesion. DWI assigned as VIRADS categories 2 and 1, respectively. Overall VIRADS score was 1 for the smaller mass and 2 for the larger. 

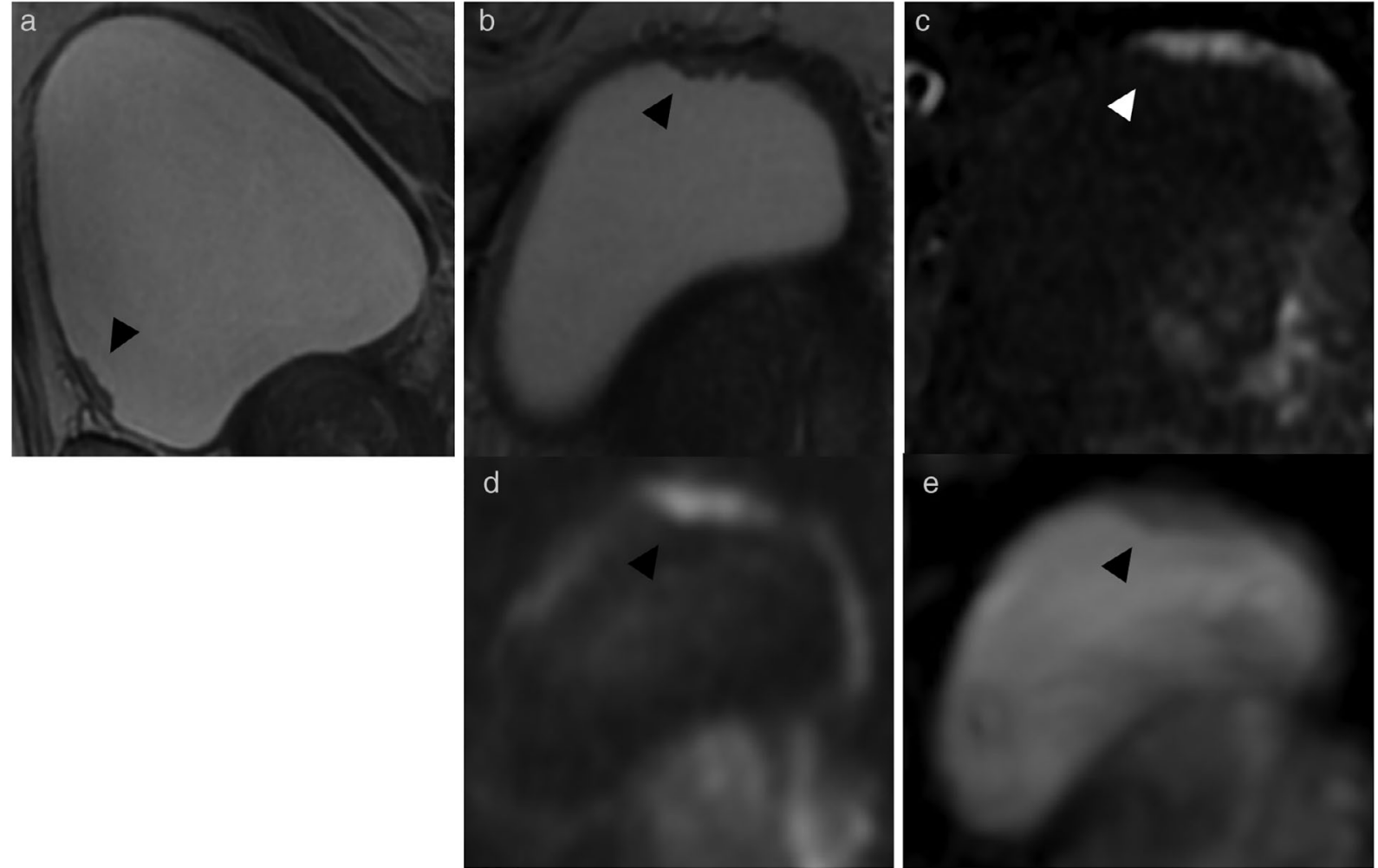

FIGURE 2: A 75-year-old male treated with TURB for NMIBC. (a,b) $T_{2} W$ imaging (sagittal, axial plane) shows a sessile mass $>1 \mathrm{~cm}$ in size (arrowhead) at the level of the anterior bladder wall, with intermediate SI that does not extend through the muscularis propria. $\mathrm{T}_{2} \mathrm{~W}$ imaging assigned as VIRADS category 2. (c) DCE imaging shows early and heterogeneous enhancement of the lesion, not clearly extending through the muscularis propria. DCE assigned as VI-RADS category 3. (d,e) DWI $(b=2000)$ and ADC maps show a lesion with significant restricted diffusion, not clearly extending through the muscularis propria. DWI assigned as VIRADS category 3. Overall VI-RADS score was 3.
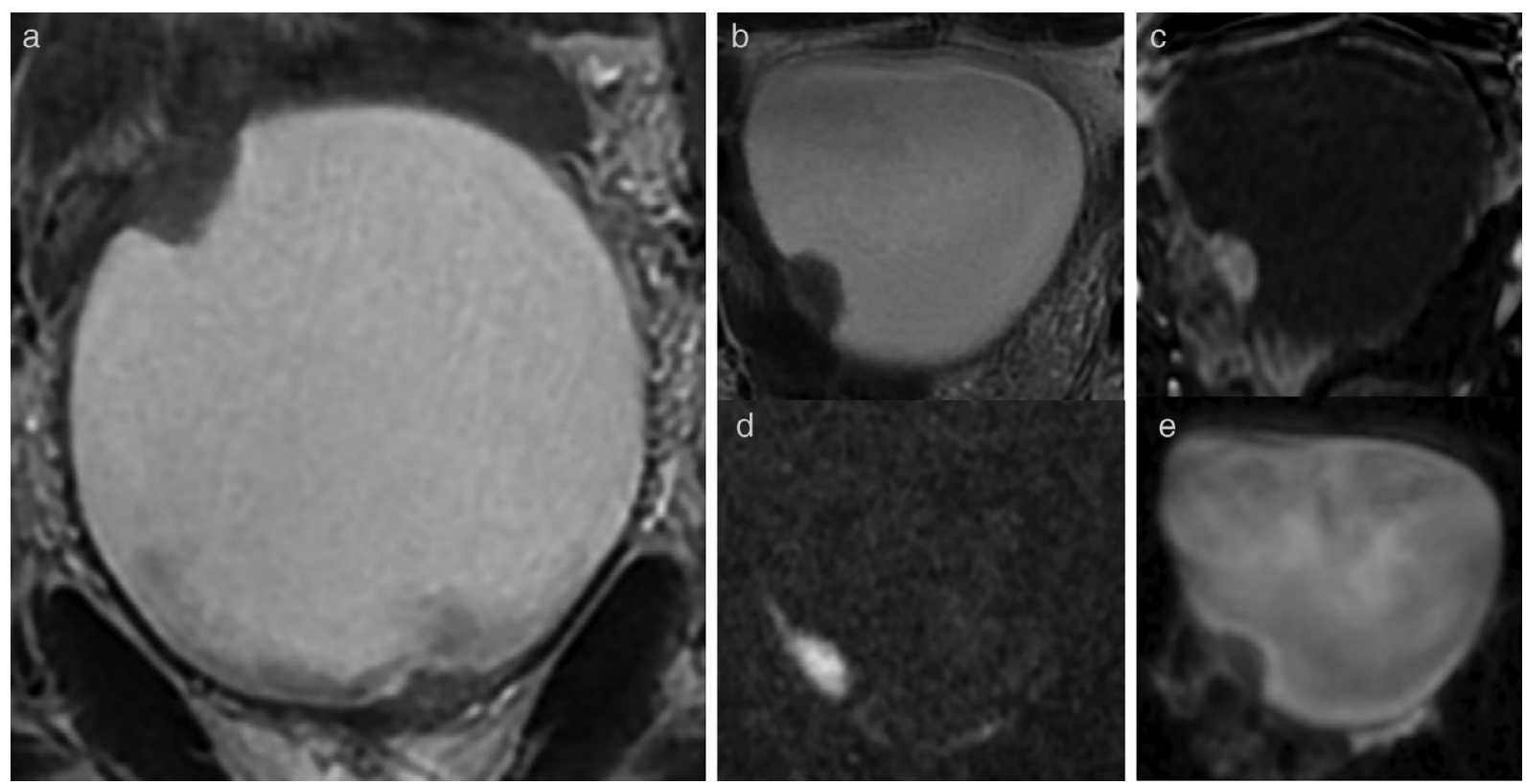

FIGURE 3: A 72-year-old male with positive cystoscopy. (a,b) $\mathrm{T}_{2} \mathrm{~W}$ imaging (coronal, axial plane) shows a sessile mass $>1 \mathrm{~cm}$ in size at the level of the right lateral bladder wall/dome of the bladder, with intermediate SI that extends through the muscularis propria. $\mathrm{T}_{2} \mathrm{~W}$ imaging assigned as VIRADS category 4. (c) DCE imaging shows early and heterogeneous enhancement of the lesion, extending through the muscularis propria. DCE assigned as VI-RADS category 4 . (d,e) DWI $(b=2000)$ and ADC maps show a lesion with significant restricted diffusion, extending through the muscularis propria. DWI assigned as VIRADS category 4 . Overall VI-RADS score was 4. 

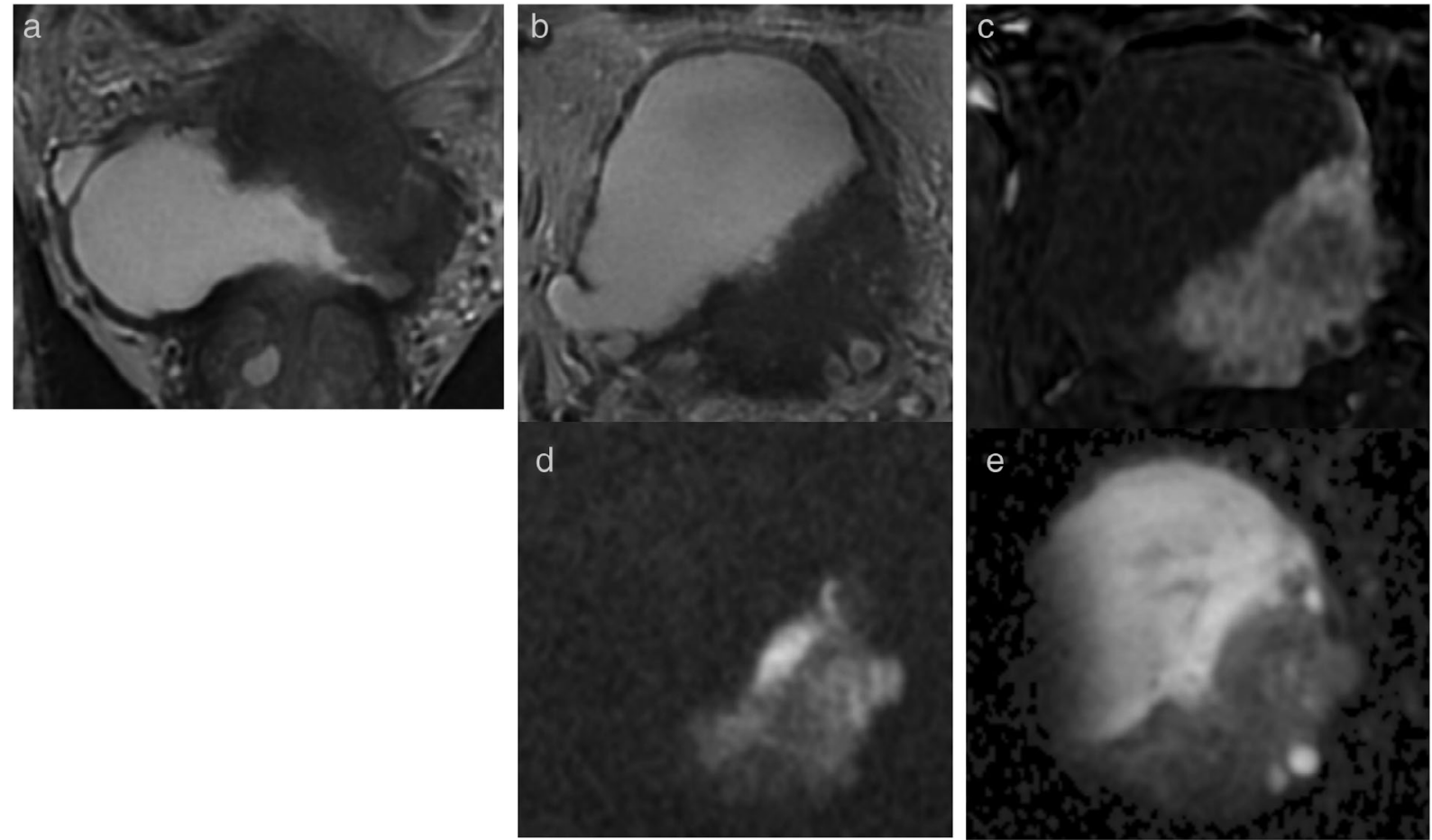

FIGURE 4: A 73-year-old male with positive ultrasound. $(a, b) T_{2} W$ imaging (coronal, axial plane) shows a sessile mass $>1 \mathrm{~cm}$ in size at the level of the posterosuperior bladder wall, with intermediate SI that extends through the muscularis propria, invading the perivesical fat tissue. $T_{2} \mathrm{~W}$ imaging assigned as VIRADS category 5. (c) DCE imaging shows early and heterogeneous enhancement of the lesion, extending through the muscularis propria, invading the perivesical fat tissue. DCE assigned as VI-RADS category 5. (d,e) DWI $(b=2000)$ and ADC maps show a lesion with significant restricted diffusion, extending through the muscularis propria, invading the perivesical fat tissue. DWI assigned as VIRADS category 5. Overall VI-RADS score was 5.

respectively ( $<\mathrm{T} 2$ stage). SC 3 is assigned to exophytic tumor without stalk, or sessile tumor with no clear disruption of low SI muscularis propria, and without a high SI thickened "inner layer." SC 4 is assigned to tumors associated with an interruption of the low SI muscularis propria still confined to the organ (T2 stage). SC 5 is assigned to tumors extending outside the bladder wall, with invasion of the perivesical fat and/or adjacent organs ( $\geq \mathrm{T} 3$ stage).

ASSESSMENT ON DWI. The single assessment on DW images defines the diffusion weighted category (DW). A bladder mass showing high SI on DWI and low SI on the ADC map extending to the muscularis propria should raise a suspicion of muscle-invasive bladder cancer ( $\geq \mathrm{T} 2$ stage). Tumor stalk and an inner layer have low SI on DWI. DW categories 1 and 2 are assigned to tumors associated with an underlining intermediate SI continuous muscularis propria, smaller or larger than $1 \mathrm{~cm}$, respectively ( $<\mathrm{T} 2$ stage). DW category 3 is assigned to tumors lacking the descriptors of categories 1 and 2 but corresponding to an SC 2 (on T2W images) and with no clear disruption of low SI muscularis propria. DW categories 4 and 5 are assigned to tumors extending to the muscularis propria (T2 stage) and through the entire bladder wall and beyond ( $\geq \mathrm{T} 3$ stage), respectively.
ASSESSMENT ON DCE. The single assessment on DCE images defines the contrast enhanced category (CE). An enhancing bladder mass associated with early enhancement of the underlining muscularis propria should raise suspicion of muscle-invasive bladder cancer ( $\geq \mathrm{T} 2$ stage). CE category 1 defines tumors corresponding to SC 1 , with no early enhancement of the muscularis propria ( $<\mathrm{T} 2$ stage). CE 2 is assigned to tumors corresponding to SC 2, with no early enhancement of the muscularis propria and with early enhancement of the inner layer ( $<\mathrm{T} 2$ stage). CE 3 is identical to DW 3. CEs 4 and 5 are assigned to early enhancing tumors extending focally to the muscularis propria (T2 stage) and through the bladder wall and beyond ( $\geq \mathrm{T} 3$ stage), respectively.

A more comprehensive summary of the single categories and overall score is described in Table 2.

\section{Diagnostic Performance}

To date, the VI-RADS score has been validated by several research groups, showing good diagnostic performance in detecting muscle-invasive bladder cancer. ${ }^{59-72}$ The first published study investigating the diagnostic accuracy and interreader reliability of the VI-RADS score was carried out by Ueno et $\mathrm{al}^{59}$ in 2019, on a retrospective cohort of 74 patients. The intraclass correlation coefficients among five readers was 
TABLE 2. T-Staging and Final VI-RADS Score According to Single Categories

\begin{tabular}{|c|c|c|c|c|}
\hline T-stage & T2WI & DCE & DWI & $\begin{array}{l}\text { Final VI-RADS } \\
\text { score }\end{array}$ \\
\hline $\mathrm{T} 1$ & $\begin{array}{l}\text { Exophytic mass }<1 \mathrm{~cm} \\
\text { with a continuous } \\
\text { underlining detrusor } \\
\text { layer }( \pm \text { stalk and } \pm \\
\text { thickened inner layer) - } \\
\text { SC } 1\end{array}$ & $\begin{array}{l}\text { No early enhancement of } \\
\text { the detrusor layer - CE } 1\end{array}$ & $\begin{array}{l}\text { Mass hyperintense on DWI } \\
\text { and hypointense on ADC } \\
\text { map with a continuous } \\
\text { underlining detrusor layer } \\
\text { on DWI - DW } 1\end{array}$ & VI-RADS 1 \\
\hline $\mathrm{T} 1$ & $\begin{array}{l}\text { Mass with a continuous } \\
\text { underlining detrusor } \\
\text { layer ( } \pm \text { hyperintense } \\
\text { thickened inner layer if } \\
\text { exophytic or with } \\
\text { hyperintense thickened } \\
\text { inner layer if sessile) - } \\
\text { SC } 2\end{array}$ & $\begin{array}{l}\text { No early enhancement of } \\
\text { detrusor layer with early } \\
\text { enhancement of inner } \\
\text { layer - CE } 2\end{array}$ & $\begin{array}{l}\text { Mass hyperintense on DWI } \\
\text { and hypointense on ADC } \\
\text { map with a continuous } \\
\text { underlining detrusor layer } \\
\text { on DWI (with hypointense } \\
\text { stalk } \pm \text { hypointense } \\
\text { thickened inner layer on } \\
\text { DWI, if exophytic; with low } \\
\text { or intermediate SI thickened } \\
\text { inner layer on DWI, if } \\
\text { sessile) - DW } 2\end{array}$ & VI-RADS 2 \\
\hline $\mathrm{T} 1$ & $\begin{array}{l}\text { Disappearance of category } \\
2 \text { findings, but no clear } \\
\text { disruption of low SI } \\
\text { detrusor layer - SC } 3\end{array}$ & CE 2 & DW 2 & VI-RADS 2 \\
\hline $\mathrm{T} 2$ & $\begin{array}{l}\text { Disappearance of category } \\
2 \text { findings, but no clear } \\
\text { disruption of low SI } \\
\text { detrusor layer - SC } 3\end{array}$ & $\begin{array}{l}\text { Lack of category } 2 \text { findings } \\
\text { with no clear disruption } \\
\text { of hypointense detrusor } \\
\text { layer - CE } 3\end{array}$ & $\begin{array}{l}\text { Lack of category } 2 \text { findings } \\
\text { with no clear disruption of } \\
\text { hypointense detrusor layer - } \\
\text { DW } 3\end{array}$ & VI-RADS 3 \\
\hline $\mathrm{T} 2$ & SC 3 & $\begin{array}{l}\text { Early enhancing mass that } \\
\text { extends focally to } \\
\text { detrusor layer - CE } \mathbf{4}\end{array}$ & $\begin{array}{l}\text { High signal-intensity tumor } \\
\text { on DWI and low } \\
\text { signal-intensity tumor on } \\
\text { ADC map extending focally } \\
\text { to detrusor layer - DW } 4\end{array}$ & VI-RADS 4 \\
\hline $\mathrm{T} 2$ & $\begin{array}{l}\text { Extension of the } \\
\text { intermediate SI tumor } \\
\text { tissue with interruption } \\
\text { of low SI line (detrusor } \\
\text { layer) - SC } 4\end{array}$ & CE 4 & DW 4 & VI-RADS 4 \\
\hline $\mathrm{T} 2$ & $\begin{array}{l}\text { Extension of intermediate } \\
\text { SI tumor to extravesical } \\
\text { fat, with invasion of the } \\
\text { extravesical tissues - SC } \\
\mathbf{5}\end{array}$ & CE 4 & DW 4 & VI-RADS 4 \\
\hline$>\mathrm{T} 2$ & SC 5 & $\begin{array}{l}\text { Tumor early enhancement } \\
\text { extends to the } \\
\text { extravesical fat - CE } 5\end{array}$ & $\begin{array}{l}\text { High signal-intensity tumor } \\
\text { on DWI and low } \\
\text { signal-intensity tumor on } \\
\text { ADC map extending to the } \\
\text { extravesical fat - DW5 }\end{array}$ & VI-RADS 5 \\
\hline
\end{tabular}


0.85 (95\% CI, 0.80-0.89) and a pooled AUC was 0.90 (95\% CI: 0.87-0.93). Wang et $\mathrm{al}^{62}$ in 2019 and Kim et $\mathrm{al}^{63}$ in 2020 published investigations with the two largest retrospective cohorts of patients, respectively 340 and 339. Both groups investigated the sensitivity, specificity, and AUC for VI-RADS scores $\geq 3$; the results achieved by Wang et al were respectively $87.1 \%$ (95\% CI: 78-93\%), 96.5\% (95\% CI: 93-98\%), and 0.94 (95\% CI: $0.90-0.98$ ); the interreader agreement between the two readers was $0.92(95 \%$ CI: $0.85-0.98)$. Kim et al showed an accuracy of $63.7 \%(95 \%$ CI: 56.4-73.2), sensitivity of $94.6 \%$ (95\% CI: 90.1-97.9), and specificity of $43.9 \%$ (95\% CI: 39.5-55.6).

In 2020, Del Giudice et $\mathrm{al}^{60}$ published the largest prospective study carried out on a cohort of 231 patients, where the authors showed a good performance of the VI-RADS score in differentiating NMIBC from MIBC, with an accuracy of 0.94 (95\% CI: 0.91-0.97); also, as a secondary aim, they examined the possible role of the VI-RADS score to stratify high-risk NMIBC patients as candidates for secondary tumor resection, demonstrating an AUC of 0.93 (95\% CI: 0.87-0.97). In March 2020, the first systematic review and meta-analysis was published by Woo et $\mathrm{al}^{66}$; it included six studies with a total of 1770 patients included. Pooled sensitivity and specificity were 0.83 (95\% CI: $0.70-0.90)$ and 0.90 (95\% CI: 0.83-0.95), and the AUC was 0.94 (95\% CI: 0.91-0.95). Factors contributing to heterogenicity among the studies were found to be significantly related to the number of patients in each study, the MRI scan magnetic field strength, the slice thickness of $\mathrm{T}_{2} \mathrm{~W}$ images, and the VIRADS cutoff score ( $\geq 3$ vs. $\geq 4$ ). Although pathologic confirmation remains the standard of reference, VI-RADS had proved to be a reliable tool to preoperatively stage $\mathrm{BCa}$, differentiating nonmuscle-invasive from muscle-invasive disease. Table 3 summarizes all published studies investigating the performance of the VI-RADS score.

\section{Discussion}

\section{Clinical Implications}

To date, the role of MRI in BCa diagnosis and staging has not yet been established.

$\mathrm{BCa}$ diagnostic and staging work-up according to European and American guidelines consists mostly of cystoscopy examination and TURBT in patients presenting with hematuria and/or suspicion of $\mathrm{BCa}$ after ultrasound exam or positive urinary cytology. Assessment of muscle invasion is essential in staging and treatment of $\mathrm{BCa}$, because therapeutic planning and prognosis are strictly related to it.

In patients with NMIBC, the prognostic risk stratification for recurrence and progression depend on multiple factors: the number of tumors, tumor size, previous recurrence rate, $\mathrm{T}$ stage, pathology grade, and the presence of concurrent CIS, according to the EORTC and CUETO models. For
NMIBC, transurethral resection with or without intravesical Bacillus Calmette-Guerin (BCG) instillations is recommended; also, radical cystectomy should be discussed with patients at highest risk of tumor progression. ${ }^{73,74} \mathrm{Up}$ to $70 \%$ of patients with NMIBC experience disease relapse within 5 years, with $20-30 \%$ of patients progressing to muscle-invasive disease despite long-term surveillance after primary therapy. ${ }^{75,76}$ The high rate of recurrence and progression to MIBC are the main factors underlying the high mortality related to $\mathrm{BCa}$. Due to high recurrence rates, often an additional tumor resection (re-TURBT) procedure within 4-6 weeks is required for NMIBC for restaging purposes, in order to avoid understaging. ${ }^{10,77-79}$ Patients with MIBC instead undergo radical cystectomy (when feasible) with or without neoadjuvant chemotherapy (NAC) or immunotherapy for patients enrolled in clinical trials. More than a third of clinically confined tumors show extravesical extension at a final pathologic examination. ${ }^{80}$ Despite improvement in surgical techniques, the rate of relapse remains high, with 5-year survival rates of $36-48 \%$ for disease staged $\geq \mathrm{pT} 3-\mathrm{T} 4$ and/or with nodal involvement, ${ }^{81}$ with an overall 5 -year mortality rate after radical cystectomy ranging from $50-70 \%{ }^{82}$

\section{Applications of VI-RADS}

The use of MRI and the VI-RADS score might fit in multiple settings. Currently, VI-RADS applicability is best suited in the pre-TURBT setting and before intravesical BCG administration. Preoperative MRI and VI-RADS scoring might be used for therapy response prediction by identifying tumors that need initially a more radical approach. ${ }^{42}$ Also, among patients with high-risk NMIBC, VI-RADS scoring might be of use for disease risk stratification and as an indication to undergo secondary resection of the tumor or to avoid it. ${ }^{60}$ However, as previously mentioned, the high tumor recurrence rate and the common need of a secondary tumor resection cannot exclude its use as a follow-up diagnostic modality for disease monitoring. In NMIBC surveillance, MRI might represent a reliable non-invasive alternative to follow-up with cystoscopy, with reduction of disease-related costs. In this setting, structural changes of the bladder wall must be considered. On $\mathrm{T}_{2} \mathrm{~W}$ images wall thickening, caused by fibrosis and inflammatory changes secondary to the surgical procedure, might be misdiagnosed as $\mathrm{BCa}$ recurrence/residue. ${ }^{42}$ To overcome such issues, the application of functional sequences, notably DCE-MRI and DWI, proved to be reliable in differentiating $\mathrm{BCa}$ from benign findings. ${ }^{36,83,84} \mathrm{In}$ the original VI-RADS document, it was suggested to perform MRI at least 2 weeks after TURBT and BCG administration in order to avoid overstaging caused by posttreatment architectural changes and at least 2 days after cystoscopy or removal of a Foley catheter to lower the risk of artifacts. However, such timing is based on expert consensus and 


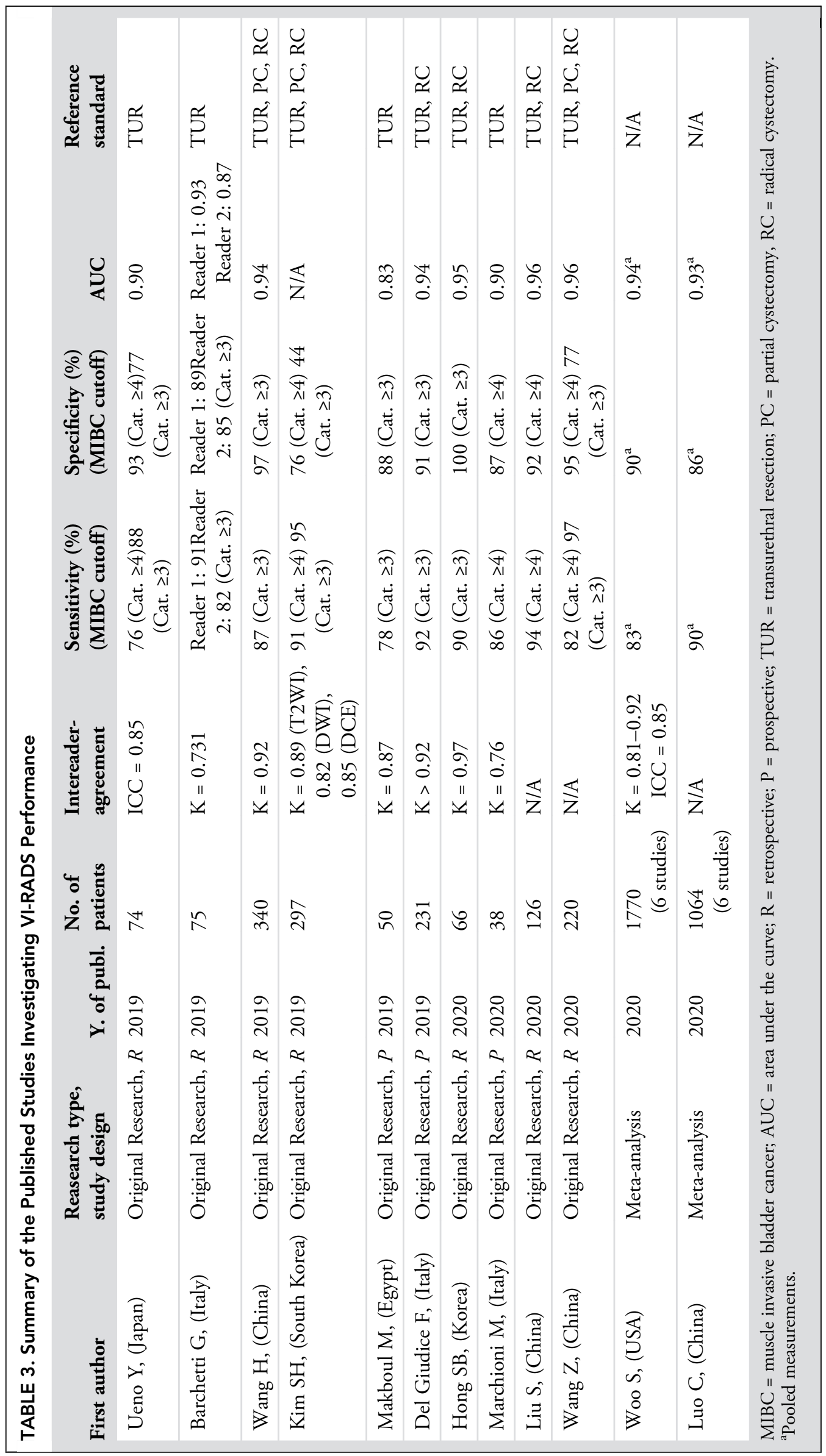


should be further clarified in future investigations to provide data-driven improvements to the scoring system.

In patients with MIBC, MRI and VI-RADS scoring might be useful to stage tumors likely to benefit from neoadjuvant therapy, to identify tumors suited for bladdersparing surgery and chemoradiation, and to plan a surgically feasible therapeutic TURBT. ${ }^{42,85,86}$

\section{Future Perspectives}

The VI-RADS score might become a tool for prediction of both tumor aggressiveness and response to therapy, as well as a clinical predictor for perioperative outcomes. Several studies have demonstrated how MRI functional sequences are reliable in determining and predicting tumor aggressiveness. ${ }^{46,87-91}$ Notably, ADC value quantification has been proposed as a potential biomarker by Kobayashi et al, showing that an ADC cutoff value of $0.86 \times 10^{-3} \mathrm{~mm}^{2} / \mathrm{s}$ (sensitivity of $88 \%$, a specificity of $85 \%$, and an accuracy of $87 \%$ ) could be used to identify clinically aggressive phenotypes differentiating high grade tumors from less aggressive phenotypes. ${ }^{92}$ A few years before Takeuchi et al proposed the $\mathrm{ADC}$ value as a predictor of $\mathrm{BCa}$ grading, there were significant differences between the values of G1 and G3 and between G2 and G3. ${ }^{33}$

Tumor response to therapy can be evaluated with the use of MRI in different clinical pictures: before, interim, and after therapy. Among others, the role of MRI was assessed by Yoshida et al in 2010 and in 2014, who proposed DWI-MRI as a biomarker to predict chemoradiation sensitivity in MIBC. ${ }^{93,94}$ More recently, Nguyen et $\mathrm{al}^{95}$ acquired a data matrix of voxelwise ADC values for each patient before NAC and correlated the results with the patient's response to chemotherapy, demonstrating that resistant tumors were more heterogeneous in their spatial distribution of ADC values. Also, Necchi et al, in 2019, demonstrated the role of MRI in the evaluation of response to therapy before and after immunotherapy, achieving promising results. ${ }^{96}$

MRI application during chemotherapy might stratify patients according to earlier prediction of treatment failure, with the main goal of reducing morbidity and costs. The efficacy of MRI in predicting response was demonstrated by Barentsz et $\mathrm{al}^{97}$ in 1998 , showing an accuracy, sensitivity, and specificity of $73 \%, 79 \%$, and $63 \%$, respectively, in distinguishing responders from nonresponders, with $\mathrm{T}_{2} \mathrm{WI}$ alone. The results went up to $95 \%, 93 \%$, and $100 \%$, respectively, when DCE-MRI was evaluated in the analysis. The crucial role of DCE in identification of chemotherapy responders was confirmed later on by other groups, reaching similar results. ${ }^{98-100}$ There is not a large body of evidence investigating the role of MRI in the posttreatment setting. Donaldson et $\mathrm{al}^{101}$ proposed DCE-MRI as a biomarker for evaluation of treatment response after radical cystectomy. Choueiri et $\mathrm{al}^{102}$ assessed the pathologic response after NAC in patients with MIBC, showing a sensitivity and specificity of $79 \%$ and $55 \%$ of DCE-MRI for determining responders, respectively.

Furthermore, MRI and VI-RADS score outcomes have been adopted as clinical predictors of a delayed time to radical interventions (ie, radical cystectomy) in the subpopulation of patients subsequently diagnosed with locally advanced extravesical BCa. In a recently published retrospective cohort series, Del. Giudice et $\mathrm{al}^{103}$ assessed the diagnostic accuracy of VI-RADS to discriminate interclass features of stage II vs. III BCa. Beyond its high overall accuracy to correlate with pathologically proven $\geq \mathrm{pT} 3$ tumors (AUC 94.2\%, 95\% CI: 88.7-99.7), the authors identified VI-RADS score 5 as an independent unfavorable predictor for significant delayed time to cystectomy (ie, $>3$ months from TURBT diagnosis of MIBC; odds ratio [OR] 2.81, 95\% CI: 1.20-6.62). The implication of such preliminary findings might lead in the future to designing clinical trials where VI-RADS could be utilized to minimize the reliance and morbidity of TURBT for MIBC detection and to aid urologists to select the cases that may require urgent radical interventions due to the presence of a high burden of disease.

The body of evidence for the widespread use of MRI in clinical practice is growing; nonetheless, it needs to be reinforced, particularly in the setting of therapy response evaluation and prediction. ${ }^{104}$

\section{Limitations and Conclusion}

Principal caveats for bladder assessment with MRI are the requirement for an adequate bladder distension, the potential need of an antispasmodic agent injection to reduce motion artifacts, the need to properly define a specific timing and possible imaging pitfalls after TURBT, BCG administration, and neoadjuvant chemo- and immune-therapy in BCa monitoring to avoid overstaging, and the lack of means to evaluate flat urothelial lesions (CIS). Nonetheless, MRI offers significant potential benefits for $\mathrm{BCa}$ staging evaluation and most of these limitations can be overcome with the support of future data-driven evidence.

VI-RADS scoring was developed in 2018 by a panel of experts to standardize evaluation and reporting of MRI for $\mathrm{BCa}$ staging. It has been proven to be a reliable tool in differentiating nonmuscle-invasive from muscle-invasive bladder cancer. It is also a promising tool in patient stratification for therapeutic planning, disease surveillance, and for the evaluation of tumor aggressiveness and response to therapy. Currently, the widespread use of the score is limited due to narrow expertise and lack of testing. Nonetheless, the VIRADS score has been consistently validated across several different institutions as an appropriate tool for local staging of $\mathrm{BCa}$ and proved to contribute to the diagnostic workup and management of bladder cancer. 


\section{Conflict of Interest}

All authors declare no conflicts of interest.

\section{Data Availability}

Data sharing is not applicable to this article, as no datasets were generated or analyzed during the current study.

\section{References}

1. Bray F, Ferlay J, Soerjomataram I, Siegel RL, Torre LA, Jemal A Global cancer statistics 2018: GLOBOCAN estimates of incidence and mortality worldwide for 36 cancers in 185 countries. CA Cancer J Clin 2018;68(6):394-424

2. Richters $A$, Aben $K K H$, Kiemeney LAML. The global burden of urinary bladder cancer: An update. World J Urol 2020;38:1895-1904.

3. van Osch FH, Jochems SH, van Schooten F-J, Bryan RT, Zeegers MP. Quantified relations between exposure to tobacco smoking and bladder cancer risk: A meta-analysis of 89 observational studies. Int J Epidemiol 2016;45(3):857-870

4. Cassell A, Yunusa B, Jalloh M, et al. Non-muscle invasive bladder cancer: A review of the current trend in Africa. World J Oncol 2019;10(3): 123-131.

5. Al-Husseini MJ, Kunbaz A, Saad AM, et al. Trends in the incidence and mortality of transitional cell carcinoma of the bladder for the last four decades in the USA: A SEER-based analysis. BMC Cancer 2019 19(1):46

6. Chamie K, Litwin MS, Bassett JC, et al. Recurrence of high-risk bladder cancer: A population-based analysis: Burden of high-risk bladder cancer. Cancer 2013;119(17):3219-3227.

7. Morris DS, Weizer AZ, Ye Z, Dunn RL, Montie JE, Hollenbeck BK Understanding bladder cancer death: Tumor biology versus physician practice. Cancer 2009;115(5):1011-1020

8. Mahdavifar $\mathrm{N}$, Ghoncheh $\mathrm{M}$, Pakzad R, Momenimovahed Z, Salehiniya $H$. Epidemiology, incidence and mortality of bladder cancer and their relationship with the development index in the world. Asian Pac J Cancer Prev 2016;17(1):381-386

9. Wong MCS, Fung FDH, Leung $C$, Cheung WWL, Goggins WB $\mathrm{Ng}$ CF. The global epidemiology of bladder cancer: A joinpoint regression analysis of its incidence and mortality trends and projection. Sci Rep 2018;8(1):1129.

10. Zapała P, Dybowski B, Poletajew S, Białek $Ł$, Niewczas A, Radziszewski $\mathrm{P}$. Clinical rationale and safety of restaging transurethra resection in indication-stratified patients with high-risk non-muscleinvasive bladder cancer. World J Surg Oncol 2018;16(1):6.

11. Gomez-Gonzalez JE, Reyes NR. Patterns of global health financing and potential future spending on health. Lancet 2017;389(10083): 1955-1956.

12. Mariotto AB, Robin Yabroff K, Shao Y, Feuer EJ, Brown ML. Projections of the cost of cancer care in the United States: 2010-2020. J Nat Cancer Inst 2011:103(2):117-128.

13. Mohamed NE, Chaoprang Herrera P, Hudson S, et al. Muscle invasive bladder cancer: Examining survivor burden and unmet needs. J Urol 2014;191(1):48-53

14. Lee CT, Mei M, Ashley J, et al. Patient resources available to bladder cancer patients: A pilot study of healthcare providers. Urology 2012 79(1):172-177.

15. Chung J, Kulkarni GS, Morash R, et al. Assessment of quality of life, information, and supportive care needs in patients with muscle and non-muscle invasive bladder cancer across the illness trajectory. Support Care Cancer 2019;27(10):3877-3885

16. Turkbey $B$, Rosenkrantz $A B$, Haider $M A$, et al. Prostate imaging reporting and data system version 2.1: 2019 update of prostate imaging reporting and data system version 2. Eur Urol 2019;76(3):340-351.
17. Chernyak V, Fowler KJ, Kamaya A, et al. Liver imaging reporting and data system (LI-RADS) version 2018: Imaging of hepatocellular carcinoma in at-risk patients. Radiology 2018;289(3):816-830

18. Pavone $\mathrm{P}$, Laghi A, Catalano C, Panebianco V, Fabiano S, Passariello R. MRI of the biliary and pancreatic ducts. Eur Radiol 1999; 9(8):1513-1522.

19. Mann RM, Cho N, Moy L. Breast MRI: State of the art. Radiology 2019;292(3):520-536

20. Hickling DR, Sun T-T, Wu X-R. Anatomy and physiology of the urinary tract: Relation to host defense and microbial infection. Microbiol Spectr 2015;3(4):1-17

21. Bolla SR, Jetti R. Histology bladder. StatPearls. Treasure Island, FL: StatPearls Publishing; 2020. http://www.ncbi.nlm.nih.gov/books/ NBK540963/.

22. Robinson BD, Khani F. Grading, staging, and morphologic risk stratification of bladder cancer. In: Hansel DE, Lerner SP, editors. Precision Molecular Pathology of Bladder Cancer. Cham, Switzerland: Springer International Publishing; 2018. p 29-42.

23. Bryan RT. Cell adhesion and urothelial bladder cancer: The role of cadherin switching and related phenomena. Phil Trans R Soc B 2015; 370(1661):20140042

24. Balci MG, Tayfur M. Loss of E-cadherin expression in recurrent noninvasive urothelial carcinoma of the bladder. Int $\mathrm{J}$ Clin Exp Patho 2018;11(8):4163-4168

25. Herr $\mathrm{H}$. Preventable cancer deaths associated with bladder preservation for muscle invasive bladder cancer. Urology 2019;130:20-21.

26. Shen $\mathrm{P}$, Lin $\mathrm{M}$, Hong $\mathrm{Y}, \mathrm{He} \mathrm{X}$. Bladder preservation approach versus radical cystectomy for high-grade non-muscle-invasive bladder cancer: A meta-analysis of cohort studies. World J Surg Oncol 2018;16 (1):197.

27. Amin MB, American Joint Committee on Cancer, American Cancer Society. AJCC cancer staging manual. Eighth edition/editor-in-chief, Amin MB, Edge SB, et al. Chicago: Springer; 2017. p 1024.

28. Caglic I, Panebianco V, Vargas HA, et al. MRI of bladder cancer: Local and nodal staging. J Magn Reson Imaging 2020;52(3):649-667.

29. de Haas RJ, Steyvers MJ, Fütterer JJ. Multiparametric MRI of the bladder: Ready for clinical routine? Am J Roentgenol 2014;202(6):11871195.

30. Lee $\mathrm{CH}$, Tan $\mathrm{CH}$, Faria $\mathrm{S}$ de $\mathrm{C}$, Kundra V. Role of imaging in the local staging of urothelial carcinoma of the bladder. Am J Roentgenol 2017;208(6):1193-1205

31. Panebianco V, Barchetti $F$, de Haas RJ, et al. Improving staging in bladder cancer: The increasing role of multiparametric magnetic resonance imaging. Eur Urol Focus 2016;2(2):113-121.

32. Narumi $Y$, Kadota $T$, Inoue $E$, et al. Bladder tumors: Staging with gadolinium-enhanced oblique MR imaging. Radiology 1993;187(1): 145-150.

33. Takeuchi M, Sasaki S, Ito $M$, et al. Urinary bladder cancer: Diffusionweighted MR imaging-Accuracy for diagnosing $T$ stage and estimating histologic grade. Radiology 2009;251(1):112-121.

34. Hayashi N, Tochigi H, Shiraishi T, Takeda K, Kawamura J. A new staging criterion for bladder carcinoma using gadolinium-enhanced magnetic resonance imaging with an endorectal surface coil: A comparison with ultrasonography. BJU Int 2000;85(1):32-36.

35. Ma W, Kang SK, Hricak H, Gerst SR, Zhang J. Imaging appearance of granulomatous disease after Intravesical Bacille Calmette-Guérin (BCG) treatment of bladder carcinoma. Am J Roentgenol 2009;192(6): 1494-1500.

36. El-Assmy A, Abou-El-Ghar ME, Refaie HF, Mosbah A, El-Diasty T. Diffusion-weighted magnetic resonance imaging in follow-up of superficial urinary bladder carcinoma after transurethral resection: Initial experience: Diffusion-weighted MRI in bladder cancer follow-up. BJU Int 2012;110(11b):E622-E627. 
37. Wang $\mathrm{H}$, Pui MH, Guan J, et al. Comparison of early submucosa enhancement and tumor stalk in staging bladder urothelial carcinoma. Am J Roentgenol 2016;207(4):797-803.

38. Narumi $Y$, Kadota $T$, Inoue $E$, et al. Bladder wall morphology: in vitro MR imaging-Histopathologic correlation. Radiology 1993;187(1): $151-155$.

39. Wang H, Pui MH, Guo Y, Yang D, Pan B, Zhou X. Diffusion-weighted MRI in bladder carcinoma: The differentiation between tumor recurrence and benign changes after resection. Abdom Imaging 2014;39 (1):135-141.

40. Zhou G, Chen X, Zhang J, Zhu J, Zong G, Wang Z. Contrast-enhanced dynamic and diffusion-weighted MR imaging at 3.0T to assess aggressiveness of bladder cancer. Eur J Radiol 2014;83(11):2013-2018.

41. Panebianco V, De Berardinis E, Barchetti G, et al. An evaluation of morphological and functional multi-parametric MRI sequences in classifying non-muscle and muscle invasive bladder cancer. Eur Radiol 2017;27(9):3759-3766

42. Panebianco $V$, Narumi $Y$, Altun E, et al. Multiparametric magnetic resonance imaging for bladder cancer: Development of VI-RADS (vesica imaging-reporting and data system). Eur Urol 2018;74(3):294-306.

43. Yu RJ, Stein JP, Cai J, Miranda G, Groshen S, Skinner DG. Superficial (pT2a) and deep (pT2b) muscle invasion in pathological staging of bladder cancer following radical cystectomy. J Urol 2006;176(2): 493-499.

44. Magers MJ, Lopez-Beltran A, Montironi R, Williamson SR, Kaimakliotis HZ, Cheng L. Staging of bladder cancer. Histopathology 2019;74(1):112-134.

45. Alfred Witjes J, Lebret T, Compérat EM, et al. Updated 2016 EAU guidelines on muscle-invasive and metastatic bladder cancer. Eur Urol 2017;71(3):462-475

46. Takeuchi M, Sasaki S, Naiki T, et al. MR imaging of urinary bladder cancer for T-staging: A review and a pictorial essay of diffusionweighted imaging: DWI of urinary bladder cancer staging. J Magn Reson Imaging 2013;38(6):1299-1309.

47. Sureka B, Kumar M, Malik A, Bhushan T, Mohanty N, Gupta N. Comparison of dynamic contrast-enhanced and diffusion weighted magnetic resonance image in staging and grading of carcinoma bladder with histopathological correlation. Urol Ann 2015;7(2):199-204.

48. Gandhi N, Krishna S, Booth CM, et al. Diagnostic accuracy of magnetic resonance imaging for tumour staging of bladder cancer: Systematic review and meta-analysis. BJU Int 2018;122(5):744-753.

49. Woo S, Suh CH, Kim SY, Cho JY, Kim SH. Diagnostic performance of MRI for prediction of muscle-invasiveness of bladder cancer: A systematic review and meta-analysis. Eur J Radiol 2017;95:46-55.

50. Huang L, Kong Q, Liu Z, Wang J, Kang Z, Zhu Y. The diagnostic value of MR imaging in differentiating $T$ staging of bladder cancer: A metaanalysis. Radiology 2018;286(2):502-511

51. Zhang $N$, Wang $X$, Wang $C$, et al. Diagnostic accuracy of multiparametric magnetic resonance imaging for tumor staging of bladder cancer: Meta-analysis. Front Oncol 2019;9:981.

52. Kim H, Lim JS, Choi JY, et al. Rectal cancer: Comparison of accuracy of local-regional staging with two- and three-dimensional preoperative 3-T MR imaging. Radiology 2010;254(2):485-492.

53. Caglic I, Povalej Brzan P, Warren AY, Bratt O, Shah N, Barrett T. Defining the incremental value of 3D T2-weighted imaging in the assessment of prostate cancer extracapsular extension. Eur Radiol 2019;29 (10):5488-5497.

54. Valerio M, Zini C, Fierro D, et al. 3T multiparametric MRI of the prostate: Does intravoxel incoherent motion diffusion imaging have a role in the detection and stratification of prostate cancer in the peripheral zone? Eur J Radiol 2016;85(4):790-794.

55. Engels RRM, Israël B, Padhani AR, Barentsz JO. Multiparametric magnetic resonance imaging for the detection of clinically significant prostate cancer: What urologists need to know. Part 1: Acquisition. Eur Urol 2019;77(4):457-468
56. Warndahl BA, Borisch EA, Kawashima A, Riederer SJ, Froemming AT. Conventional vs. reduced field of view diffusion weighted imaging of the prostate: Comparison of image quality, correlation with histology, and inter-reader agreement. Magn Reson Imaging 2018;47:67-76.

57. Paner GP, Montironi R, Amin MB. Challenges in pathologic staging of bladder cancer: Proposals for fresh approaches of assessing pathologic stage in light of recent studies and observations pertaining to bladder histoanatomic variances. Adv Anat Pathol 2017;24(3): 113-127.

58. Xiao G-Q, Rashid H. Bladder neck urothelial carcinoma: A urinary bladder subsite carcinoma with distinct clinicopathology. Int J Surg Pathol 2015;23(7):517-523.

59. Ueno $Y$, Takeuchi $M$, Tamada $T$, et al. Diagnostic accuracy and interobserver agreement for the vesical imaging-reporting and data system for muscle-invasive bladder cancer: A multireader validation study. Eur Urol 2019;76(1):54-56.

60. Del Giudice F, Barchetti G, De Berardinis E, et al. Prospective assessment of vesical imaging reporting and data system (VI-RADS) and its clinical impact on the management of high-risk non-muscle-invasive bladder cancer patients candidate for repeated transurethral resection. Eur Urol 2020;77(1):101-109.

61. Barchetti G, Simone G, Ceravolo I, et al. Multiparametric MRI of the bladder: Inter-observer agreement and accuracy with the vesical imaging-reporting and data system (VI-RADS) at a single reference center. Eur Radiol 2019;29(10):5498-5506.

62. Wang H, Luo C, Zhang F, et al. Multiparametric MRI for bladder cancer: Validation of VI-RADS for the detection of detrusor muscle invasion. Radiology 2019;291(3):668-674.

63. Kim $\mathrm{SH}$. Validation of vesical imaging reporting and data system for assessing muscle invasion in bladder tumor. Abdom Radiol 2019;45(2): 491-498.

64. Makboul M, Farghaly S, Abdelkawi IF. Multiparametric MRI in differentiation between muscle invasive and non-muscle invasive urinary bladder cancer with vesical imaging reporting and data system (VI-RADS) application. BJR 2019;92(1104):20190401.

65. Hong SB, Lee NK, Kim S, et al. Vesical imaging-reporting and data system for multiparametric MRI to predict the presence of muscle invasion for bladder cancer: Accuracy of VI-RADS in bladder cancer. J Magn Reson Imaging 2020.

66. Woo S, Panebianco V, Narumi Y, et al. Diagnostic performance of vesical imaging reporting and data system for the prediction of muscleinvasive bladder cancer: A systematic review and meta-analysis. Eur Urol Oncol 2020;3(3):306-315

67. Luo C, Huang B, Wu Y, Chen J, Chen L. Use of vesical imagingreporting and data system (VI-RADS) for detecting the muscle invasion of bladder cancer: A diagnostic meta-analysis. Eur Radiol 2020;30(8): 4606-4614.

68. Pecoraro M, Takeuchi M, Vargas HA, et al. Overview of VI-RADS in bladder cancer. Am J Roentgenol 2020;214(6):1259-1268.

69. Hechler V, Rink M, Beyersdorff D, et al. Bedeutung der VI-RADSKlassifikation für die Bildgebung beim Harnblasenkarzinom - Stand der Dinge. Urologe 2019;58(12):1443-1450.

70. Wang Z, Shang Y, Luan T, et al. Evaluation of the value of the VI-RADS scoring system in assessing muscle infiltration by bladder cancer. Cancer Imaging 2020;20(1):26.

71. Marchioni M, Primiceri G, Delli Pizzi A, et al. Could bladder multiparametric MRI be introduced in routine clinical practice? Role of the new VI-RADS score: Results from a prospective study. Clin Genitourin Cancer 2020; epub ahead of print.

72. Liu S, Xu F, Xu T, Yan Y, Yao X, Tang G. Evaluation of vesical imaging-reporting and data system (VI-RADS) scoring system in predicting muscle invasion of bladder cancer. Transl Androl Urol 2020;9(2):445-451.

73. Babjuk M, Burger M, Compérat EM, et al. European Association of Urology guidelines on non-muscle-invasive bladder cancer (TaT1 and carcinoma in situ) - 2019 update. Eur Urol 2019;76(5):639-657. 
74. https://www.auanet.org/guidelines/bladder-cancer-non-muscleinvasive-guideline\#x3701. 202AD.

75. Zhu C-Z, Ting H-N, Ng K-H, Ong T-A. A review on the accuracy of bladder cancer detection methods. J Cancer 2019;10(17):4038-4044.

76. Aldousari S, Kassouf W. Update on the management of non-muscle invasive bladder cancer. Can Urol Assoc J 2010;4(1):56-64.

77. Brausi M, Collette L, Kurth K, van der Meijden AP, et al. Variability in the recurrence rate at first follow-up cystoscopy after TUR in stage ta T1 transitional cell carcinoma of the bladder: A combined analysis of seven EORTC studies. Eur Urol 2002;41(5):523-531.

78. Richterstetter M, Wullich B, Amann K, et al. The value of extended transurethral resection of bladder tumour (TURBT) in the treatment of bladder cancer: Value of extended turbt for treating bladder cancer. BJU Int 2012;110(2b):E76-E79

79. Herr HW, Donat SM. Quality control in transurethral resection of bladder tumours. BJU Int 2008;102(9b):1242-1246.

80. Shariat SF, Palapattu GS, Karakiewicz PI, et al. Discrepancy between clinical and pathologic stage: Impact on prognosis after radical cystectomy. Eur Urol 2007;51(1):137-151.

81. Hautmann RE, Gschwend JE, de Petriconi RC, Kron M, Volkmer BG Cystectomy for transitional cell carcinoma of the bladder: Results of a surgery only series in the neobladder era. J Urol 2006;176(2):486-492.

82. Park JC, Citrin DE, Agarwal PK, Apolo AB. Multimodal management of muscle-invasive bladder cancer. Curr Probl Cancer 2014;38(3): 80-108.

83. Barentsz JO, Jager GJ, van Vierzen PB, et al. Staging urinary bladder cancer after transurethral biopsy: Value of fast dynamic contrastenhanced MR imaging. Radiology 1996;201(1):185-193.

84. Johnson RJ, Carrington BM, Jenkins JPR, Barnard RJ, Read G, Isherwood I. Accuracy in staging carcinoma of the bladder by magnetic resonance imaging. Clin Radiol 1990;41(4):258-263.

85. Seisen T, Sun M, Lipsitz SR, et al. Comparative effectiveness of trimodal therapy versus radical cystectomy for localized muscleinvasive urothelial carcinoma of the bladder. Eur Urol 2017;72(4): 483-487.

86. International Collaboration of Trialists on behalf of the Medical Research Council Advanced Bladder Cancer Working Party (now the National Cancer Research Institute Bladder Cancer Clinical Studies Group), the European Organisation for Research and Treatment of Cancer Genito-Urinary Tract Cancer Group, the Australian Bladder Cancer Study Group, the National Cancer Institute of Canada Clinical Trials Group, Finnbladder, Norwegian Bladder Cancer Study Group and Club Urologico Espanol de Tratamiento Oncologic. International phase III trial assessing neoadjuvant cisplatin, methotrexate, and vinblastine chemotherapy for muscle-invasive bladder cancer: Long-term results of the BA06 30894 trial. JCO 2011;29(16):2171-2177.

87. Yoshida S, Takahara T, Kwee TC, Waseda Y, Kobayashi S, Fujii Y. DWI as an imaging biomarker for bladder cancer. Am J Roentgenol 2017 208(6):1218-1228.

88. Kikuchi K, Shigihara T, Hashimoto $Y$, et al. Apparent diffusion coefficient on magnetic resonance imaging (MRI) in bladder cancer: Relations with recurrence/progression risk. FJMS 2017;63(2):90-99.

89. Abdelsalam EM, EL Adalany MA, Fouda MEA. Value of diffusion weighted magnetic resonance imaging in grading of urinary bladder carcinoma. Egypt J Radiol Nucl Med 2018;49(2):509-518.
90. Yamada Y, Kobayashi S, Isoshima S, Arima K, Sakuma H, Sugimura Y. The usefulness of diffusion-weighted magnetic resonance imaging in bladder cancer staging and functional analysis. J Can Res Ther 2014; 10(4):878-882.

91. Matsuki M, Inada Y, Tatsugami F, Tanikake M, Narabayashi I, Katsuoka Y. Diffusion-weighted MR imaging for urinary bladder carcinoma: Initial results. Eur Radiol 2007;17(1):201-204.

92. Kobayashi S, Koga F, Yoshida S, et al. Diagnostic performance of diffusion-weighted magnetic resonance imaging in bladder cancer: Potential utility of apparent diffusion coefficient values as a biomarker to predict clinical aggressiveness. Eur Radiol 2011;21(10):2178-2186.

93. Yoshida S. Diffusion-weighted magnetic resonance imaging in management of bladder cancer, particularly with multimodal bladdersparing strategy. WJR 2014;6(6):344-354.

94. Yoshida S, Koga F, Kawakami S, et al. Initial experience of diffusionweighted magnetic resonance imaging to assess therapeutic response to induction chemoradiotherapy against muscle-invasive bladder cancer. Urology 2010;75(2):387-391.

95. Nguyen HT, Mortazavi A, Pohar KS, et al. Quantitative assessment of heterogeneity in bladder tumor MRI diffusivity: Can response be predicted prior to neoadjuvant chemotherapy? BLC 2017;3(4): 237-244.

96. Necchi A, Bandini M, Calareso G, et al. Multiparametric magnetic resonance imaging as a noninvasive assessment of tumor response to neoadjuvant pembrolizumab in muscle-invasive bladder cancer: Preliminary findings from the PURE-01 study. Eur Urol 2019;77(5): 636-643.

97. Barentsz JO, Berger-Hartog O, Witjes JA, et al. Evaluation of chemotherapy in advanced urinary bladder cancer with fast dynamic contrast-enhanced MR imaging. Radiology 1998;207(3):791-797.

98. Chakiba C, Cornelis F, Descat E, et al. Dynamic contrast enhanced MRI-derived parameters are potential biomarkers of therapeutic response in bladder carcinoma. Eur J Radiol 2015;84(6):1023-1028.

99. Schrier BP, Peters M, Barentsz JO, Witjes JA. Evaluation of chemotherapy with magnetic resonance imaging in patients with regionally metastatic or unresectable bladder cancer. Eur Urol 2006;49(4): 698-703.

100. Nguyen HT, Jia G, Shah ZK, et al. Prediction of chemotherapeutic response in bladder cancer using K-means clustering of dynamic contrast-enhanced (DCE)-MRI pharmacokinetic parameters: Chemotherapeutic response in bladder cancer. J Magn Reson Imaging 2015; 41(5):1374-1382

101. Donaldson SB, Bonington SC, Kershaw LE, et al. Dynamic contrastenhanced MRI in patients with muscle-invasive transitional cell carcinoma of the bladder can distinguish between residual tumour and post-chemotherapy effect. Eur J Radiol 2013;82(12):2161-2168.

102. Choueiri TK, Jacobus S, Bellmunt J, et al. Neoadjuvant dose-dense methotrexate, vinblastine, doxorubicin, and cisplatin with pegfilgrastim support in muscle-invasive urothelial cancer: Pathologic, radiologic, and biomarker correlates. JCO 2014;32(18):1889-1894.

103. Del Giudice F, Leonardo C, Simone G, et al. Preoperative detection of VI-RADS (vesical imaging-reporting and data system) score 5 reliably identifies extravesical extension of urothelial carcinoma of the urinary bladder and predicts significant delayed time-to-cystectomy: Time to reconsider the need. BJU Int 2020. epub ahead of print.

104. O'Connor JPB, Aboagye EO, Adams JE, et al. Imaging biomarker roadmap for cancer studies. Nat Rev Clin Oncol 2017:14(3):169-186. 